Scientific Electronic Archives

Issue ID: Sci. Elec. Arch. Vol. 14 (11)

November 2021

DOI: http://dx.doi.org/10.36560/141120211457

Article link: https://sea.ufr.edu.br/SEA/article/view/1457

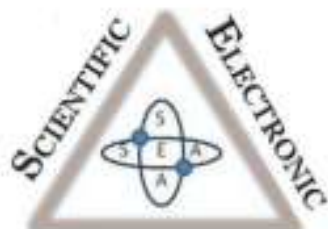

ArCHIVES

ISSN 2316-9281

\title{
Desenvolvimento florestal em sistema integrado lavoura-pecuaria-floresta
}

\author{
Forest development in an integrated crop-livestock-forestry system
}

\author{
Corresponding author \\ Luciana Christina Alves Lopes \\ Universidade Estadual de Goiás, \\ lucianachristina2013@hotmail.com
}

Alessandro José Marques Santos

Universidade Estadual de Goiás

Clarisse Backes

Universidade Estadual de Goiás

Larissa da Luz Silva

Universidade Estadual de Goiás

Ângelo Ferreira Magalhães

Universidade Estadual de Goiás

\begin{abstract}
Resumo: Frente a uma realidade de crescimento populacional e produção com sustentabilidade, os sistemas integrados se apresentam de forma positiva, atentando principalmente ao componente florestal que permanece mais tempo no sistema. Diante a necessidade crescente de produtividade, a integração lavoura pecuária floresta (ILPF) caracteriza-se pela agregação de ciclos agrícolas e pecuários, em sequência na mesma área de produção, e sem afetar os recursos do sistema. Considerando que apresentam uma sinergia entre si, no ILPF é preciso adequar seus componentes, o nível tecnológico e efetuar um planejamento detalhado para garantia de sucesso do sistema. $\mathrm{O}$ integrante florestal deve ser escolhido e instalado com cautela visando o objetivo de produção, e o desenvolvimento dos demais integrantes. A espécie florestal mais utilizada hoje no país é o eucalipto, pois apresenta rápido crescimento, capacidade de adaptação às diversas regiões ecológicas e pelo potencial econômico proporcionado pela utilização diversificada de sua madeira. Algumas das espécies mais difundidas para plantios de eucalipto no país são Eucalyptus cloeziana, comumente usada para reflorestamento, híbridos de E. grandis x E. urophylla (E. Uroghrandis), destinado principalmente para serraria e Corymbia Citriodora, anteriormente classificadas como Eucalyptus, utilizada principalmente para produção de óleos essenciais. Diante da expectativa de produção sustentável do sistema ILPF, são necessárias a síntese de informações técnicas e científicas acerca dos melhores modelos para instalação e condução do sistema em função da diversidade ambiental e socioeconômica. O objetivo deste trabalho é a síntese de informações bibliográficas a respeito do desenvolvimento do sistema ILPF.
\end{abstract}

Palavras-chave: Componente florestal, Eucalipto, ILPF, Sistemas integrados.

Abstract: Faced with a reality of population growth and sustainable production, integrated systems present themselves in a positive way, paying particular attention to the forest component that remains in the system longer. In view of the growing need for productivity, the integration of forest livestock farming (ILPF) is characterized by the aggregation of agricultural and livestock cycles, in sequence in the same production area, and without affecting the resources of the system. Considering that they present a synergy with each other, in the ILPF it is necessary to adapt its components, the technological level and carry out a detailed planning to guarantee the success of the system. The forestry member must be chosen and installed with care, aiming at the production objective and the development of the other members. The forest species most used today in the country is eucalyptus, as it has fast growth, adaptability to different ecological regions and the economic potential provided by the diversified use of its wood. Some of the most widespread species for eucalyptus plantations in the country are Eucalyptus cloeziana, commonly used for reforestation, hybrids of $E$. grandis $x$ 
E. urophylla (E. Uroghrandis), destined mainly for sawmills and Corymbia Citriodora, previously classified as Eucalyptus, mainly used for the production of essential oils. Given the expectation of sustainable production of the ILPF system, it is necessary to synthesize technical and scientific information about the best models for installing and conducting the system due to environmental and socioeconomic diversity. The objective of this work is the synthesis of bibliographic information about the development of the ILPF system.

Keywords: Forest component, Eucalyptus, ILPF, Integrated systems.

\section{Introdução}

A produção global de alimentos ameaça a estabilidade climática e a capacidade dos ecossistemas, impondo a quem produz adotarem sistemas que sejam sustentáveis. Não apenas para produzirem alimentos suficientes com o objetivo de alimentar uma população crescente, mas também produzir uma diversidade que sustentam a saúde humana e apoiem a sustentabilidade ambiental (GLOBAL ENVIRONMENT FACILITY, 2019).

Os sistemas de integração lavoura pecuária floresta (ILPF) visa desenvolver de forma harmônica três ramos mais utilizados na agricultura do país. São estudados e recomendados por se tratarem de sistemas integrados que proporcionam um desenvolvimento e complementariedade da qualidade de solo, envolvendo atributos físicos, químicos e biológicos, a variação da produtividade das propriedades, e a evolução das circunstâncias microclimáticas da região, incluindo a diminuição da emissão de gases e da taxa de desmatamento de florestas nativas (DE VECHI \& MAGALHAES JUNIOR, 2018).

Dentro do sistema ILPF o componente agrícola trata de culturas anuais como milho, e no componente pecuário a espécie mais disseminada é a Urochloa (braquiaria). Segundo Rodrigues et al. (2019) o componente que fica mais tempo na área de produção é o florestal e isso requer uma maior atenção a espécie e ao modelo de arranjo escolhido, considerando que o seu desenvolvimento e dos demais componentes podem ser influenciados.

O componente florestal dentro dos sistemas integrados ocasiona alterações na água, luz, nutrientes, entre outros. Alguns benefícios citados na literatura envolvem o desenvolvimento do ambiente radicular e maior aporte de carbono orgânico no solo (SILVA et al., 2021).

A principal espécie arbórea escolhida para cultivos integrados no Brasil é o eucalipto, ele possui uma variedade grande de espécies e híbridos permitindo o direcionamento no momento da escolha de acordo com a finalidade, e condições de solo e clima do local de plantio. A área total de árvores cultivadas no Brasil é de nove milhões de hectares, desse total o eucalipto ocupa7,6 milhões de hectares (IBGE, 2019).

O eucalipto possui rápido crescimento e capacidade própria de adaptação em diferentes ambientes. Possui boa disponibilidade de radiação solar incidente no sub-bosque, sendo uma das razões para sua indicação aos sistemas integrados (RADOMSKI e RIBASKI, 2010).

Mesmo possuindo uma plantação de floresta para obtenção de energia florestal ainda pequena, o Brasil se encontra em pleno desenvolvimento nessa área, buscando atender às demandas e exigências atuais de produção.

Müller (2018), afirma que estudos acerca dos detalhes, desenvolvimento e benefícios do sistema são essenciais para levantamento das informações dos melhores arranjos adaptados à realidade de cada área, pois diversificar a produção na propriedade desperta um conceito de integração de atividades muito encorajador.

Com base no que foi apresentado, objetivou-se com esse trabalho apresentar os resultados de uma revisão bibliográfica a respeito do desenvolvimento do componente florestal em sistemas ILPF.

\section{Contextualização e análise}

O desenvolvimento sustentável é aquele capaz de satisfazer as necessidades presentes sem comprometer a capacidade das gerações futuras de suprir suas necessidades.

A agricultura brasileira está caminhando para se tornar cada vez mais eficiente e sustentável. Como evidência houve um salto produtivo dos últimos anos, no qual foi possível obter relevante aumento de produtividade das culturas sem aumento significativo das áreas cultivadas, apresentando na safra 2019/2020 área cultivada de 68,5 milhões de hectares e produção de 273,8 milhões de toneladas, crescimento de $6,5 \%$ de produção em relação à safra de 2018/2019, e apenas 3,9\% de incremento na área (CONAB, 2019).

Diante o cenário mundial de crescimento populacional e demanda crescente por alimentos torna-se cada vez mais importante produzir de forma sustentável, a fim de garantir a alimentação humana, a conservação de solos e os diferentes ecossistemas (RIBEIRO, 2017).

O contexto de sustentabilidade e como alcançá-la vêm crescendo por meio de pesquisa e estudos ao longo dos anos no Brasil e no mundo. Tópicos como resíduos florestais e preservação ambiental são amplamente discutidos e sustentados por acordos e legislações cada vez mais minuciosos (SILVA \& CAVICHIOLI, 2020).

O país se destaca como um dos líderes e protagonista na construção de uma nova economia, é possível observar a extensão da contribuição 
nacional e o esforço despendido para alcançar os princípios de sustentabilidade ambiental, com a adoção de sistemas de produção de baixo carbono (Telles et al., 2021).

Para os cientistas da comissão EAT-Lancet (2020), a eliminação de lacunas de produção em terras agrícolas, usos eficientes de fertilizantes e água, reciclagem de fósforo e redistribuição do uso de nitrogênio e fósforo e 0 aumento da biodiversidade dentro dos sistemas agrícolas são os pontos principais para elevar a produção e impulsioná-la a sustentabilidade e inovação.

De acordo com Pereira et al. (2018), o maior desafio do setor agrícola é produzir de forma sustentável, e os sistemas integrados são o destaque para alcançar esse desafio, pois além de promover a sustentabilidade, gera efeitos rápidos e resultados na oferta da produção.

O desempenho agrícola é imprescindível para a produção de alimentos. Um dos principais entraves dos sistemas integrados instalados na atualidade é 0 baixo nível de eficiência, diversificação e rentabilidade acentuada pela falta de planejamento e deficiência hídrica dos últimos anos. O sistema global de produção de alimentos deve-se basear em intensificação sustentável e inovação de sistemas produtivos (CORDEIRO et al., 2015).

O fato de demandar produzir mais com maior eficiência e diversificação em um mesmo espaço, além de gerenciar os recursos solo e água de maneira eficiente gera a intensificação sustentável. Os sistemas de integração são exemplos de produção fundamentados na sustentabilidade por gerarem vários benefícios de natureza tecnológica, ecológica e ambiental, econômica e social (MENDES et al., 2021).

A diversificação da produção se apresenta de forma positiva as propriedades rurais, pois 0 mercado agropecuário brasileiro é incerto e volúvel, assim a alta de alguns produtos compensa a baixa de outros, tornando o capital investido seguro. Agregando diversas cadeias produtivas componentes da agricultura, pecuária e florestas cultivadas, o mercado agropecuário vem se mantendo como um segmento importante para a economia brasileira (TELLES et al., 2021).

Balbino et al. (2011) subdividiu os sistemas integrados em quatro modalidades, o ILP (integração lavoura pecuária- agropastoril), o ILPF (integração lavoura pecuária e florestaagrossilvipastoril), o IPF (integração pecuária floresta - silvipastoril) e o ILF (integração lavoura floresta- silviagricola).

De acordo a Plataforma ABC da Embrapa, dos mais de 15 milhões de hectares com sistema produtivo integrado, estima-se que em 2018, cerca de $17 \%$ da área total de ILPF sejam provenientes de integração da lavoura e/ou pecuária com o setor de árvores plantadas, o equivalente a 2,55 milhões de hectares (IBÁ, 2020).
As tecnologias empregadas no sistema de integração são responsáveis pelos resultados crescentes da produção agropecuária e denotam a maior eficiência do setor. Em 2005, a área destinada aos sistemas de ILPF era de aproximadamente 1,87 milhões de hectares. Em 2018, esse valor passou para 15 milhões de hectares, ou seja, no período de treze anos, essa área ficou oito vezes maior. Enquanto isso a produtividade crescia de 140 para 257milhões de toneladas, conforme dados levantados por Telles et al., (2021).

A incorporação do cultivo de árvores e lavouras com a pecuária se desenvolve como caminho para transformação da situação de propriedades tradicionais em sustentáveis. Assim de maneira racional o homem aplica diversos plantios caminhando entre culturas anuais e perenes, e incluindo o componente animal tornando o conjunto produtivo. No Brasil tais sistemas começam a ser inseridos a partir da década de 60 (TOMAZ \& WANDER, 2017).

O processo de produção ILPF divulga a utilização de espécies florestais, agrícolas e a criação de animais, numa mesma área, de maneira simultânea e, escalonada no tempo. O sistema é apontado por proporcionar proteção do solo contra a erosão, conservação da água, manutenção do ciclo hidrológico e melhoria dos atributos físicos, químicos e biológicos do solo (ASSIS et al., 2019) (BONINI et al., 2016), aumento do valor nutricional da forragem e do conforto térmico animal, melhorias no desempenho de bovinos criados a pasto (ALVES et al., 2019), benefícios socioeconômicos tais como diversificação da produção e da renda, redução do risco da atividade e redução da sazonalidade da demanda por mão - de obra no campo (MÜLLER et al., 2018).

Com coeficientes técnicos e operacionais, insumos e serviços, estudados em ambientes de produção comercial com quatro níveis tecnológicos, determinou-se que com o planejamento da implantação de sistemas ILPF o produtor poderá garantir elevado potencial de geração de receitas em longo prazo, principalmente com componente florestal. Além do ganho direto do sistema ainda se garante no componente ambiental fixação de CO2 e melhorando a biodiversidade (GONTIJO NETO et al., 2020).

As fases de rotação e sucessão da cultura também são extremamente importantes dentro do sistema, garantindo a integração dos componentes, conhecer o processo de adoção e ajustá-lo tecnicamente frente às condições ambientais, econômicas e tecnológicas das apresentadas pela propriedade (SKORUPA \& MANZATTO, 2019).

Os modelos de integração lavoura pecuária floresta estão se mostrando com alta perspectiva para regiões de relevo mais acidentado como apontado por Müller (2018), e os entraves principais se tratam do manejo adotado pelo produtor, 
monitoramento frequente e investimentos mais altos que mono cultivo demonstrado por Ferreira (2019).

Frente ao problema ambiental atual, a preocupação internacional acerca das mudanças climáticas que envolvem alguns setores produtivos e principalmente a agropecuária, devido à produção de gases de efeito estufa (GEE) (CINTRA, 2020), foram criadas políticas públicas nacionais que financiam a implantação de sistemas integrados, o chamado Plano ABC - Agricultura de Baixa emissão de Carbono. O programa estabelece sete programas entre eles as metas para adoção de ILPF até 2030 dentro do país (BRASIL, 2018).

Para que os SIPAs possa ser utilizado de uma maneira ampla, Balbinot Júnior et al. (2017) sugere uma parceria entre agricultores e pecuaristas. Isso permite a utilização de modelos em que haja um especialista de cada área, gerando uma sinergia entre a produção animal e vegetal.

Silva et al. (2020) afirmou em seus estudos sobre o nível de conhecimento dos produtores que 94\% alegaram que nunca tiveram uma proposta de implantação do método SIPAs em suas propriedades. Além disso, não recebem planejamento e execução de produção por um técnico (70\%). Menos da metade dos entrevistados deste estudo disse ser pouco provável utilizar os SIPAs em suas propriedades (46\%). A implantação do SIPAs ainda é baixa pelo desconhecimento, o que sugere maior atuação de conscientização e divulgação do método.

O aumento da lucratividade é a chave de interesse para levar o sistema às propriedades rurais, todavia os incrementos em sustentabilidade socioambiental não podem ser ignorados e estudos a cerca desses custos serão cada vez mais oportunos (RIBEIRO, 2017).

Para Pereira et al. (2018) todos os sistemas integrados são economicamente consideráveis desde que haja uma indústria florestal previamente estabelecida e com expectativa de crescimento.

Compreendendo que alguns mercados sempre estarão com condições diferentes de outros, a diversificação das receitas e despesas do sistema se apresenta de forma positiva. E deve-se considerar a importância dos centros de pesquisa para transferência de tecnologias e as políticas públicas de fomento (PEREIRA et al., 2019) (MENDES et al., 2021).

Conscientizar da melhor forma o produtor, foi pré-determinado para que a transferência de tecnologia deva acontecer em todo território brasileiro, adequando-se à locais com maior probabilidade de instalação e desenvolvimento do sistema e com racionalização de recursos humanos e financeiros para auxiliar no planejamento da implementação (TOMAZ \& WANDER, 2017).

Em propriedades especializadas em pecuária de corte, os planejamentos dos sistemas integrados devem levar em consideração fatores de ambiente externo, como clima, comunicação, financiamento, infraestrutura externa, assistência técnica e mercado, e fatores de ambiente interno como, expectativas, solo, mão de obra, econômico, infraestrutura interna e gestão. Os SIPAs precisam de planejamento mais acurado e contínuo, e a cada ano o planejamento deve ser atualizado, sobretudo o operacional (BENDAHAN et al., 2018).

No caso de propriedades com foco em produção vegetal, a inserção de animais requer planejamento da forrageira, pastos, estruturas de manejo e cochos. Além disso o planejamento forrageiro é indispensável na propriedade, sendo necessário considerar a produção esperada, a qualidade da forragem e os períodos de maior e menor produção de cada espécie forrageira inserida no sistema, seja anual ou perene. A possibilidade de produção de certa quantidade de forragem conservada, (silagem ou feno), para utilização em momentos em que a pastagem apresenta baixa capacidade de suporte, ou em períodos secos também precisa ser levada em consideração (BALBINOT JUNIOR et al., 2017).

O componente florestal tem grande importância para a economia, fornece matérias primas, é base florestal para grandes empreendimentos de indústrias siderúrgicas, para produção de carvão, papel, celulose, madeira, postes, bioenergia, construção civil, entre outros. Ainda se tem a contribuição para a conservação ambiental e de espécies nativas através da redução da exploração sobre os recursos florestais (SNIF, 2020).

O setor florestal representou em 2020 1,2\% do PIB nacional com receita bruta total de $\mathrm{R} \$ 97,4$ bilhões, mesmo em anos difíceis como 2019, geraram oportunidades a 3,75 milhões de brasileiros em todo o país e até 2023 deve criar mais 36 mil novos postos de trabalho (IBÁ, 2020).

O Brasil tem grande disponibilidade de terras para cultivos florestais, entretanto se apresentam pouco exploradas, e extensas áreas degradadas que poderiam ser convertidas em plantios florestais (OLIVEIRA \& OLIVEIRA, 2017).

Assis e Resende (2011) afirmam que a função primordial das florestas plantadas é de produzir e em contrapartida garantir o desenvolvimento sustentável, sendo fonte de produtos e matérias primas renováveis ou fonte de renda e de serviços ambientais.

Os plantios florestais atualmente estão inseridos em regiões antropizadas de relevo acidentado, áreas agrícolas degradadas e solos de baixa fertilidade. Tais condições relacionadas ao potencial erosivo, colheita mecanizada e operações de manejo são os responsáveis pela perda da capacidade produtiva dos solos e alteração da quantidade e qualidade das águas em bacias, decorrentes de erosões hídricas. Este fator pode ser ajustado pelo plantio em nível e sistemas de manejo que ofereçam cobertura de solo (Silva e Schwartz, 2019) (SILVA et al., 2011). 
O uso final da madeira, as condições edafoclimáticas e o mercado consumidor também influenciam na escolha da espécie a ser incorporada no sistema (RIBEIRO et al., 2017). A quantidade de informações a respeito do manejo tem crescido frequentemente, aumentando a facilidade de encontrar mudas e a destinação da madeira produzida.

Nos sistemas de integração, as árvores estão dispostas de maneira que não prejudiquem as práticas agrícolas e promovam melhores condições de microclima para os animais. O manejo das árvores deve ser definido quando se planeja a implantação do sistema e deve fazer parte de uma das atividades que visem um produto final bem definido. Os espaçamentos amplos e arranjos alocados em renques específicos melhoram os níveis de rendimento para todos os componentes (FERREIRA et al., 2019).

Moreira et al. (2017) afirma que sistemas de produção mais longos com finalidade no uso múltiplo apresentam rentabilidades superiores aos cultivos para único produto. Florestas plantadas podem representar investimentos atrativos para os produtores rurais, com ganhos semelhantes aos da agricultura, se bem planejados.

Santana et al. (2019) em seus estudos com componente arbóreo, demonstrou que as condições ambientais e as características das pastagens influenciam o deslocamento de bovinos em SIPAs, de acordo com o conforto térmico promovido pelas árvores.

Weimann et al. (2017) estudou que os plantios florestais são mais viáveis economicamente, que os sistemas agroflorestais, quando comparado apenas o componente florestal, entretanto os sistemas agrossilvipastoris, são uma alternativa de renda para os pequenos produtores rurais, pois além de produtos da silvicultura contam com a diversificação da produção com agricultura e pecuária, além dos benefícios ambientais.

Há de se notar o caráter de longo prazo do sistema, absorvendo os benefícios do sombreamento $e$, adequando seu controle por desrama e desbaste, inclusive incluindo tais fatores no planejamento do silvicultor (MÜLLER et al., 2018).

Para o componente florestal, dentro de um aspecto técnico, o arranjo espacial e a densidade das árvores abalam os parâmetros de investimentos, e causam um entrave entre altos custos iniciais para implementação e benefícios de longo prazo, é importante que o produtor tenha um bom planejamento inicial que contemple uma análise de risco (FERREIRA et al., 2019).

De acordo com Ribeiro et al. (2017), avaliando produção de biomassa florestal em sistemas de integração, afirmou que sistemas que incluem pastagem e animais apresentam menor oferta de madeira e menor escala para biomassa.
Para Magalhães et al. (2018), o componente florestal em ILPF pode alterar o microclima em seu interior melhorando índices de conforto térmico em até $20 \%$ nas áreas de sombra projetadas por árvores e as condições de criação e desempenho dos animais dependendo dos fatores relacionados à instalação do sistema como orientação, espaçamento e época do ano.

Mortari et el. (2019) em seus experimentos sobre sombreamento avaliou a quantidade de FDA e FDN em diferentes pastagens afirmando que a orientação do renque $\mathrm{L} / \mathrm{O}$ e N/S influencia na produção de fibras da pastagem, principalmente para Mombaça.

Ortiz et al. (2019) avaliando a interferência do sombreamento no cultivo da soja afirma que a produtividade do componente do sistema nas linhas mais próximas aos renques independente da orientação dos renques de eucaliptos foi reduzida, enquanto as linhas mais centrais entre os renques tiveram produtividades maiores.

O componente agrícola, cultivado na entressafra em período de menor disponibilidade hídrica, é afetado pelo componente florestal com maior intensidade pela competição por água do solo (MARCHIORO, 2019).

A presença do componente arbóreo em ecossistemas de pastagens pode interferir de forma diferente nas características do solo, o que indica necessidade específica de manejo da fertilidade para cada tipo de sistema (PACIULLO \& GOMIDE, 2019).

Várias são as espécies arbóreas com potencial para compor um sistema de ILPF, pinus, teca, acácia e seringueira, entretanto o eucalipto tem sido a mais utilizada, principalmente por seu potencial de crescimento, diversidade de utilização da madeira e crescimento monopodial.

Os gêneros Eucalyptus são originários da Austrália, possuem aproximadamente 730 espécies. Porem apenas 20 são atualmente plantadas para fins comerciais no mundo. As espécies mais utilizadas, em função das características de suas madeiras, são: Eucalyptus grandis, Eucalyptus saligna, Eucalyptus urophylla, Eucalyptus viminalis, híbridos de E. grandis $x$ E. urophylla e Eucalyptus dunnii e Eucalyptus benthamii para Região Sul do Brasil (PINTO JUNIOR et al., 2014).

Os aspectos técnicos mais importantes para decidir as espécies que se deve investir para plantios de eucaliptos, são os seguintes: clima; solo; dimensão da área; sistema de cultivo; principal finalidade de uso e sistema de colheita; dentre outros (SANTOS \& PALUDZYSZYN FILHO, 2014).

Em 2019 o cultivo do eucalipto representou $77 \%$ das áreas de florestas plantadas, com 6,97 milhões de hectares, e o Brasil apresentou uma produtividade média de $35,3 \mathrm{~m} 3$ /ha ao ano (IBÁ, 2020).

No ano de 2017, a participação do setor de eucalipto somou $\mathrm{R} \$ 73,8$ bilhões a economia 
brasileira, representando cerca de $1,1 \%$ do Produto Interno Bruto (PIB) nacional e $6,1 \%$ do industrial. No mesmo período, o Brasil bateu recorde na produção de celulose, chegando a 19,5 milhões de toneladas do produto, e passando ao segundo lugar mundial, tendo ultrapassado o Canadá e a China (IBÁ, 2017).

A madeira do Eucalyptus foi responsável por grande parte da pasta celulósica produzida no país na última década, em que o $E$. grandis e seus híbridos interespecíficos têm uma expressiva participação. Conhecer as características da madeira é primordial para obtenção de produtos com qualidade desejável. A produtividade é abrangente, estando relacionado tanto com as características das matérias-primas, como com as ações de manejo e técnicas operacionais que poderão garantir a padrões homogêneos (DIAS \& SIMONELLI, 2013).

Para Tonini (2019), mudas de eucalipto plantadas em sistemas de monocultivo e silvipastoril não apresentaram influência sobre biomassa individual, entretanto as árvores plantadas no último manejo citado demonstraram uma maior conicidade do tronco, menor altura total e maior biomassa alocada à copa.

Cerqueira et al. (2019) afirmou que o espaçamento e arranjo de plantio influenciam de forma significativa na relação hipsométrica, implicando que não se deve utilizar uma única equação para representar a relação $\mathrm{h} / \mathrm{d}$ para dados globais que contemplem diferentes espaçamentos e arranjo de plantio de eucalipto em sistemas iLPF.

Em seu estudo Oliveira et al. (2015) determinou, avaliando a altura do eucalipto que é influenciada pelo consórcio com acácia nos arranjos estudados na integração lavoura-pecuária-floresta (ILPF), o que não acontece com o diâmetro altura do peito, proporcionando produtividade de madeira igual ao arranjo simples, e a produtividade de madeira de eucalipto menor no consorcio, a madeira produzida pelas duas espécies no arranjo composto é superior ao cultivo apenas de eucalipto na linha de plantio.

Cipriani (2018) em seu trabalho sobre potencial de crescimento do eucalipto em dois renques diferentes aponta sobre a importância do planejamento e ainda recomenda o uso de espaçamento de 3,5 m x 3,0 m entre plantas para proporcionar árvores grossas e evitar perda de produtividade por área.

De acordo com Cerqueira et al. (2021) o volume de árvores de determinado plantio ou renque pode ser detalhado utilizando modelos matemáticos que são instrumentos válidos no meio florestal para que seja determinada a quantificação volumétrica. Os modelos de efeitos mistos demonstraram grande potencial para o componente florestal apresentando maior eficiência para volume de Eucalipto em ILPF.
Os estudos técnicos e científicos dos impactos ambientais do plantio do eucalipto e os conhecimentos já adquiridos ao longo do tempo dessa cultura em território brasileiro, somados às boas perspectivas do manejo bem-estruturado já aplicadas neste segmento, recomendam a continuidade da atividade econômica (COSTA \& OLIVEIRA, 2019).

O melhoramento genético do eucalipto no Brasil é praticado principalmente pelas indústrias de celulose, papel e aço. Mas também é realizado por diversas empresas industriais e pela Embrapa Florestas. Outras instituições que contribuem para o melhoramento do eucalipto são as universidades Universidade Federal de Viçosa/ Sociedade de Investigação de Florestas (UFV / SIF), Escola Superior de Agricultura 'Luiz de Queiroz'(ESALQ), Universidade de São Paulo (USP), Instituto de Pesquisa e Estudos Florestais(IPEF), Universidade Federal de Lavras (UFLA), Universidade Federal do Paraná (UFPR) e Universidade Estadual Paulista(UNESP), gerando teses e estudos sobre 0 tema. Alguns deles também fornecem sementes melhoradas (ASSIS \& RESENDE, 2011).

O Eucalyptus cloeziana é uma espécie comumente utilizada para reflorestamento, por apresentar madeira resistente e durável, é característico o crescimento lento nos três primeiros anos, mas acelera nos seguintes, a madeira é utilizada para diversos fins, no Brasil (MOURA, 2003).

O Eucalyptus cloeziana possui boa forma de fuste, durabilidade natural e resistência a insetos e fungos, entretanto são sensíveis a geadas. A madeira produzida é destinada para fins energéticos (queima direta e carvão natural), construções civis e instalações rurais (FERREIRA et al., 2019).

De acordo com os resultados encontrados no trabalho de Alves (2017), as amostras de madeiras de Eucalyptus cloeziana apresentaram densidade básica, densidade aparente seca, densidade aparente com umidade e densidade aparente a $12 \%$ de umidade, com valores aparentes estáveis, demonstrando uma madeira estável de variação volumétrica com $19,68 \%$. Sendo assim consideradas menos propensas ao fendilhamento, rachaduras e empenamentos.

Pertuzzatti et al. (2017) demonstrou que a madeira do $E$. cloeziana é mais resistente a impactos na condição saturada em comparação com condições climatizada e seca, e apresentou maior capacidade de absorver energia e dissipa-la por meio de deformações não devendo ser utilizadas em locais sujeitos a cargas de choque.

Radomski e Ribaski (2010) demonstrou em seus experimentos com Corymbia citriodora que o manejo silvicultural da espécie é importante para manter os expressivos valores de excentricidade de medula, e árvores com diferentes formas e tamanhos de fuste interferem nos resultados 
mesmo em árvores com qualidade elevada. Além disso, o resultado da heterogeneidade das plantas foi devido ao descuido com a origem e a uniformidade das mudas à época do plantio.

O sistema silvipastoril composto pela urochloa brizantha e pelo Corymbia citriodora mostrou-se viável para a região paranaense, em função de não apresentar diferença na quantidade de nitrogênio (proteína bruta) disponível para os animais, em relação à testemunha, e pelo adicional de madeira produzido na área (204 m3ha-1) (RIBASKI et al., 2019).

A espécie Corymbia citriodora é recomendada para áreas não afetadas por geadas, apresenta boa resistência a déficits hídricos e sua madeira é destinada para serraria e para produção de postes, mourões, lenha e carvão. Em solos pobres pode apresentar bifurcações ligadas a deficiências nutricionais principalmente relacionadas ao boro (FERREIRA et al., 2019).

Corymbia citriodora também apresenta fisiologia adaptável as condições de clima da maior parte do Brasil têm incremento volumétrico e forma de fuste interessante e também sua madeira pode ser utilizada para diversos fins, incluindo serralheria. Esse fato deve-se as propriedades da madeira e por tratamentos preventivos apresentarem alto efeito nesse produto, somadas essas características tornam sua utilização interessante. (REIS et al., 2003).

O eucalipto Urograndis exerce maior efeito competitivo pela água do solo que o eucalipto Citriodora, resultando em maior efeito supressivo à produtividade do componente agrícola em sistema ILPF (MARCHIORO, 2019).

A inclusão dessa espécie em sistemas integrados, com vistas à diversificação da produção, pode se tornar uma importante alternativa de renda aos pequenos e médios produtores rurais, principalmente pelo potencial da espécie para usos múltiplos.

O Eucalyptus urophylla grandemente difundido no Brasil, adapta-se as diversas condições climáticas brasileiras e pode ser utilizado para finalidade de produção de celulose, painéis de fibras, serraria, postes dormentes e carvão. O clone I144 (E. urophylla) é amplamente cultivado, apresenta alta eficiência na utilização de nutrientes e é tolerante a déficits hídricos (PALUDZYSZYN FILHO \& SANTOS, 2013).

Cripriani et al. (2013) ao avaliar o crescimento de 4 clones de E. urophylla e $E$. grandis e híbridos desses o 1144 apresentou 0 maior volume de produção e crescimento de $40 \mathrm{~m}^{3}$ ha-1 ano-1.

Eucalyptus urograndis apresentaram os melhores desempenhos no acúmulo de biomassa seca e nas variáveis fisiológicas auferidas no período entre 120-240 dias após semeadura. Essa espécie surge como alternativa promissora no florestamento com espécies nativa e maior evapotranspiração (SOUZA et al., 2018).

Através da seleção de uma população base composta de espécies ajustadas a certo empreendimento e que passam por uma seleção e avaliação exaustiva é que darão origem a clones de alto desempenho que atingirão padrão de produtividade satisfatório (SILVA et al., 2003).

Bochetti (2015), em seus estudos com clones verificou que quanto maior a inclinação do tronco maior a excentricidade de medula encontrada, e não existe aspecto relacionando tal fator à posição de tronco em sentido longitudinal.

Ferreira et al. (2016) avaliaram o crescimento de três clones de eucalipto plantados em linha simples, dupla e tripla até os 32 meses, em sistema integrado, observaram que a altura não foi influenciada pelo arranjo. A maior produtividade foi observada nos arranjos mais densos, sendo de $100 \mathrm{~m}^{3} / \mathrm{ha}$ no arranjo triplo, $90 \mathrm{~m}^{3} / \mathrm{ha}$ no arranjo duplo e $60 \mathrm{~m}^{3} / \mathrm{ha}$ no arranjo simples. O maior diâmetro à altura do peito (DAP) $0,20 \mathrm{~m}$, e maior volume individual, $0,17 \mathrm{~m}^{3}$ por árvores foi observado no arranjo simples ao passo que entre os arranjos duplos e triplos não foram observadas diferenças $(p<0,05)$.

\section{Considerações finais}

O sistema ILPF se caracteriza como um meio para garantir a produção de alimentos e a sustentabilidade. Integrando os componentes do sistema lavoura pecuária e floresta que complementam entre si e garantem a sinergia dos mesmos, diversificando a produção e aumentando a produtividade.

O planejamento e a implementação bem feitos do ILPF garantem as vantagens do sistema, e bons coeficientes de produção. O desenvolvimento de políticas públicas de incentivo e fomento também são pontos cruciais de incentivo a implantação desse sistema nas propriedades. É imprescindível que o método seja mais divulgado e alcance 0 maior número de propriedades, além de incentivar mais estudos voltados para área, demonstrando os resultados e despertando 0 interesse dos produtores.

O componente florestal no sistema tem grande importância desde a produção de madeira, aumentando a rentabilidade, 0 aumento do consumo em relação ao comportamento alimentar dos animais. Apesar de estes sistemas serem conhecidos desde a década de 60 , ainda são necessárias muitas informações técnicas e cientificas sobre a implantação e a condução.

Com o objetivo de diminuir adversidades do sistema, e garantir a produtividade e desenvolvimento dos componentes, em especial o componente florestal, são essenciais o desenvolvimento de pesquisas e estudos acerca do ILPF nas mais diversas regiões do país. 


\section{Referências}

ALVES, F. V.; PORFÍRIO-DA-SILVA, V.; KARVATTE JUNIOR, N. Bem-estar animal e ambiência na ILPF. Embrapa Gado de CorteCapítulo em livro científico (ALICE), 2019.

ALVES, R. C.; OLIVEIRA, A. L.C.; CARRASCO, E. V. M. Propriedades Físicas da Madeira de Eucalyptuscloeziana F. Muell. Floresta Ambient. Seropédica, 2179-8087, 2017.

ASSIS, T. F.; DE RESENDE, M. D. V. Melhoramento genético de espécies florestais arbóreas. CropBreed. Appl. Biotechnol. Viçosa, 1984-7033, 2011.

ASSIS, P. C. R.; STONE, L. F.; MEDEIROS, J. C.; MADARI, B. E.; OLIVEIRA, J. de M.; WRUCK., F. J. Atributos físicos do solo em sistemas de integração lavoura-pecuária-floresta. Revista Brasileira Engenharia Agrícola Ambiental, Campina Grande, 0103-9954, abr. 2015.

BALBINO, L C.; BARCELLOS, A. de O.; STONE, L. F. Marco referencial: integração lavoura-pecuáriafloresta. Embrapa Cerrados - Livro científico (ALICE), 2011.

BALBINOT JUNIOR, A. A.; MORAIS, A. de; CONTE, O.; FRANCHINI, J. C.; DEBIASI, H. Produção integrada de grãos e pecuária: oportunidade para aumentar a diversificação e a rentabilidade. Embrapa Soja-Artigo em anais de congresso (ALICE). Pato Branco, 2017.

BENDAHAN, A. B.; POCCHARD, R.; MEDEIROS, R. D de; MOURÃO FILHO, M.; LUCENA; N. da C.; BRAGA; R. M.; TOURRAND, J. F. Sistemas integrados de produção agropecuária em pequenas e médias propriedades rurais. Agricultural Reserch for Development. Cap. 12. Pág. 211. 2018. https://agritrop.cirad.fr/589690/1/CAP_12.pdf.

BONINI, C. dos S. B.; Lupatini, G. C.; ANDRIGHETTO, C.; MATEUS, G. P.; HEINRICHIS, R.; ARANHA, A. S.; SANTANA, E. A. R.; MEIRELLES, G. C. Produção de forragem e atributos químicos e físicos do solo em sistemas integrados de produção agropecuária. Pesquisa agropecuária brasileira, 0100-204x. 2016.

BOSCHETTI, W. T. N.; PAES, J. B.; VIDAURE, G. B.; ARANTES, M. D. C.; LEITE, F. P. Parâmetros dendrométricos e excentricidade da medula em árvores inclinadas de eucalipto. Scientia Forestalis. Piracicaba. 1413-9324, 2015.

BRASIL. MINISTÉRIO DA AGRICULTURA, PECUÁRIA E ABASTECIMENTO. Plano setorial de mitigação e de adaptação às mudanças climáticas para a consolidação de uma economia de baixa emissão de carbono na agricultura: plano $A B C$ (Agricultura de Baixa Emissão de Carbono) /Ministério da Agricultura, Pecuária e Abastecimento, Ministério do Desenvolvimento Agrário, coordenação da Casa Civil da Presidência da República. - Brasília: MAPA/ACS, 2012.173 p. ISBN 978-85- 7991-062-0.

CAMPANHA, M. M.; COSTA, T. C. C.; NETO, M. M. G.; REZENDE, A. V.; SIMÃO, E. P.; BORGHI, E.; OLIVEIRA, A. C.; KALITA, L. Intensificação agropecuária no Cerrado: crescimento do eucalipto em ILPF sob diferentes níveis de investimento tecnológico. Embrapa Milho e Sorgo-Circular Técnica (INFOTECA-E), 2020.

CERQUEIRA, C. L.; MÔRA, R.; TONINI, H.; ARCE, J. E.; LISBOA, G. DOS S.; DINIZ, C. C. C.; CARVALHO, S. DE P. Modelagem do volume de eucalipto em sistema de integração LavouraPecuária-Floresta. Advances in Forestry Science, 2357-8181, 2021.

CERQUEIRA, C. L.; MÔRA, R.; TONINI, H.; VENDRUSCOLO, D. G. S.; LANSSANOVA, L. R.; ARCE, J. E.; DINIZ, C. C. C. Efeito do espaçamento e arranjo de plantio na relação hipsométrica de eucalipto em sistema consorciado de produção. Nativa, Sinop, 2318-7670, 2019.

CINTRA, P. H. N.; DE MELO, O. F. P.; DE MENEZES, J. O. S.Produção agrícola: uma revisão bibliográfica sobre as mudanças climáticas e produtividade de plantas graníferas no brasil. Revista Agrotecnologia, Ipameri, 2179-5959, 2020.

CIPRIANI, H. N.; VIEIRA, A. H.; GODINHO, V. Crescimento inicial de clones de eucalipto em Vilhena, RO. Embrapa Rondônia-Comunicado Técnico (INFOTECA-E), 2013.

CIPRIANI, H. N.; VIEIRA, A. H.; PASSOS, A. M. A. dos; CARMO, C. C. A. do.; VIEIRA, D. da S. Crescimento de eucaliptos em dois espaçamentos dentro do renque em sistema iLPF. Embrapa Rondônia-Artigo em anais de congresso (ALICE). Anais. Colombo- PR: Embrapa Florestas. 447 p. 2018.

CONAB. Acompanhamento da safra brasileira grãos. SAFRA 2018/19 - N. 9 - Nono levantamento. Brasília. https://www.conab.gov.br/infoagro/safras/graos/boletim-da-safra-de-graos.

CORDEIRO, L. A. M.; VILELA, L.; KLUTHCOUSKI, J.; MARCHAO, R. L. Integração lavoura-pecuáriafloresta: 0 produtor pergunta, a Embrapa Responde. Área de Informação da Sede - Col Criar Plantar ABC 500P/500R Saber (INFOTECA-E), Brasília- DF. 2015. 
COSTA, B. S.; OLIVEIRA, M. L. Florestas plantadas de eucalipto no brasil: uma cultura nociva aos recursos hídricos? Veredas do Direito: Direito Ambiental e Desenvolvimento Sustentável, 21798699. 2019.

DE VECHI, A.; MAGALHÃES JÚNIOR, C. A. de O. Aspectos positivos e negativos da cultura do eucalipto $e$ os efeitos ambientais do seu cultivo. Revista Valore, 2523-043X, 2018.

DIAS, O. A.; SIMONELLI, G. QUALIDADE DA MADEIRA PARA A PRODUÇÃO DE CELULOSE E PAPEL. ENCICLOPÉDIA BIOSFERA, Centro Científico Conhecer - Goiânia, v.9, n.17; p. 3633. 2013.

https://www.conhecer.org.br/enciclop/2013b/MULTI DISCIPLINAR/qualidade\%20da\%20madeira.pdf

EAT-Lancet - Alimento Planeta Saúde, Dietas saudáveis a partir de sistemas alimentares sustentáveis, $2020 . \quad \mathrm{https}$ ://irpcdn.multiscreensite.com/63a687e5/files/uploaded/E AT-

Lancet_Commission_Summary_Report_Portugese. pdf

FARIA, G. E. de; BARROS, N. F.; CUNHA, V. L. P.; MARTINS, I. S.; MARTINS, R. de C. C. Avaliação da produtividade, conteúdo e eficiência de utilização de nutrientes em genótipos de Eucalyptus spp. no vale do Jequitinhonha, MG. Ciência Florestal, Santa Maria 1980-5098, 2008.

FERREIRA, A. D.; SERRA, A. P.; LAURA, V. A.; ORTIZ, A. C. B.; ARAUJO, A. R. de; PEDRINHO, D. R.; CARVALHO, A. M. Influence of spatial arrangements on silvicultural characteristics of three Eucalyptus clones atintegratedcrop-livestock-forest system. Embrapa Gado de Corte-Artigo em periódico indexado (ALICE), 2016.

FERREIRA, A. D.; SERRA, A. P.; MELOTTO, A. M.; BUNGENSTAB, D. J.; LAURA, V. A. Manejo das árvores e propriedades da madeira em sistema de ILPF com eucalipto. Embrapa Café-Capítulo em livro científico (ALICE), 2019.

GLOBAL ENVIRONMENT FACILITY. Safeguarding the Global commons: The Seventh Replenishment of the global Environment Facility. Washington, 2019.

https://www.thegef.org/sites/default/files/publications /GEF_safeguarding_global_commons_May2019_C RA.pdf.

GONTIJO NETO, M. M.; RESENDE, A. V. de; BORGHI, E.; CAMPANHA, M. M.; COSTA, T. C. e C. da; SIMÃO, E. de P.; GIEHL, J.; ABREU, S. C.; ALVARENGA, R. C. Intensificação agropecuária no Cerrado: coeficientes técnicos e análise financeira de Sistemas ILPF com diferentes níveis de investimento tecnológico. Embrapa Milho e SorgoCircular Técnica (INFOTECA-E), 2020.

IBÁ - INDÚSTRIA BRASILEIRA DE ÁRVORES. Relatório $2017 . \quad$ Brasília. https://iba.org/datafiles/publicacoes/pdf/ibarelatorioanual2017.pdf.

IBÁ INDÚSTRIA BRASILEIRA DE ÁRVORES. Relatório Anual lbá 2020. São Paulo: Café Art, 2020.

https://iba.org/datafiles/publicacoes/relatorios/relator io-iba-2020.pdf.

INSTITUTO BRASILEIRO DE GEOGRAFIA E ESTATISTICA (IBGE). Extração vegetal e silvicultura. $\quad$ Brasil. 2019. https://cidades.ibge.gov.br/brasil/pesquisa/16/0.

MAGALHÃES, C. A. de S.; ZOLIN, C. A.; LULU, J.; LOPES, L.B. Índices de conforto térmico em sistemas de integração lavoura-pecuária-floresta (ILPF) no ecótono Cerrado/Amazônia. Embrapa Agrossilvipastoril-Boletim de Pesquisa e Desenvolvimento (INFOTECA-E), 2018.

MARCHIORO, V. Influência do componente florestal na produtividade agrícola em sistemas de integração lavoura-pecuária-floresta. 44 Folhas. Repositório UNESP. (Dissertação de mestrado) 2019. http://hdl.handle.net/11449/190812.

MENDES, R. T.; CORDEIRO, S. A.; LEITE, A. M. P.; OLIVEIRA, R. J.; COUTO, L. C.; GODOY, T. M.; GUERRA, C. A.; GONTIJO, R. N. Sistemas agroflorestais como geração de renda no Norte de Minas e no Alto Jequitinhonha. Silvicultura e manejo florestal. Técnicas de Utilização e Conservação da Natureza - 1414-5219, 2021.

MOREIRA, J. M. M. Á. P.; SIMIONI, F. J.; DE OLIVEIRA, E. B. Importância e desempenho das florestas plantadas no contexto do agronegócio brasileiro. Floresta, v. 47, n. 1, p. 85-94,1982-4688 2017.

MORTARI, D. G., REIS, R. H. P. dos, SOUZA, F. G. de, PADILHA, F. da S., AGUIAR, A. A. de, Bazzi, K. J. B., RUFINO, R. J. da S., SALMORIA, G. do A.Influência do sombreamento sobre as frações fibrosas dos capins convert hd364 e mombaça em sistema de integração lavoura-pecuária-floresta. I SimSIPA, p. 51, 2019.

MOURA, V. P. G. O germoplasma de Eucalyptus cloeziana F. MUELL. no Brasil. Brasília-Distrito Federal. Embrapa Recursos Genéticos E Biotecnologia. 2003. https://www.infoteca.cnptia.embrapa.br/infoteca/bitst ream/doc/185459/1/cot102.pdf . 
MÜLLER, M. D.; CALSAVARA, L. H. F.; BRIGHENTI, A. M.; MARTINS, C. E.; PACIULLO, D. S. C. Manejo silvicultural em sistemas de integração lavoura-pecuária-floresta. Embrapa Gado de LeiteCapítulo em livro técnico (INFOTECA-E), 2018.

OLIVEIRA, F. L. R. de; CABACINHA, C. D.; SANTOS, L. D. T.; BARROSO, D. G.; SANTOS JÚNIOR, A. dos; BRANT, M. C.; SAMPAIO, R. A. Crescimento inicial de eucalipto e acácia, em diferentes arranjos de integração lavoura-pecuáriafloresta. CERNE, Lavras, v. 21, n. 2, p. 227-233, 2317-6342 junho 2015.

OLIVEIRA, Y. M. M. de; OLIVEIRA, E. B. de. Plantações florestais: geração de benefícios com baixo impacto ambiental. Embrapa Florestas-Livro científico (ALICE), 2017.

ORTIZ, R. J.; MARINHO, R. D.; BALBINO, E.; SOUZA, F. G. de; PASSOS, E. F., COUTO, E. R.; RUFINO, R. J. da S.; AGUIAR, A. A. de. Interferência do sombreamento na produtividade de soja semeada entre renques de eucaliptos em sistemas de integração lavoura-pecuária-floresta. I $\begin{array}{llll}\text { SimSIPA, } & \text { p. } & 42 . & \end{array}$ https://portal.ifro.edu.br/images/Campi/Colorado_do _Oeste/Documentos/Anais_1_SimSIPA_-v2.pdf\#page $=60$.

PACIULLO, D. S. C; GOMIDE, C. A. de M. Manejo de pastagens tropicais em sistemas silvipastoris. Embrapa Gado de Leite-Capítulo em livro técnico (INFOTECA-E), $2019 .$.

PALUDZYSZYN FILHO, E.; SANTOS, P. E. T. Escolha de cultivares de eucaliptos em função do ambiente e do uso. Comunicado Técnico 316. Colombo- PR. 2013.

PEREIRA, S. E. M.; MANZATTO, C. V.; SKORUPA, L. A.; PENTEADO, M. I. de O.; OLIVEIRA, P. de; NOVAES, N. M. L. N.; SIMÕES, M. G. Análise multicritério para planejamento em sistemas de integração lavoura, pecuária e floresta. Embrapa Meio Ambiente-Documentos (INFOTECA-E), 2018.

PEREIRA, M. de A.; COSTA, F. P.; DE ALMEIDA, R. G. Viabilidade econômica da introdução de eucalipto em Sistemas de Integração LavouraPecuária. In: Embrapa Gado de Corte-Artigo em anais de congresso (ALICE). IN: CONGRESSO DA SOCIEDADE BRASILEIRA DE ECONOMIA, ADMINISTRAÇÃO E SOCIOLOGIA RURAL, 56. Anais... Campinas: SOBER, 2018.

PEREIRA, S. E. M.; SKORUPA, L. A.; MANZATTO, C. V. Áreas prioritárias para ações de transferência de tecnologia em integração lavoura, pecuária e floresta no estado de São Paulo. Embrapa Meio
Ambiente-Artigo em anais de congresso (ALICE). Anais. São José dos Campos: INPE, 2019.

PERTUZZATTI, A.; CONTE, B., MISSIO, L.; GATTO, D. A.; HASELEIN, C. R.; SANTINI, E. J. Influência da Umidade na Resistência da Madeira de Eucalipto a Impactos. Floresta e Ambiente, v. 24, 2179-8087, 2017.

PINTO JUNIOR, J. E.; SANTAROSA, E.; GOULART, I. C. G. R. Histórico do cultivo de eucalipto. Cultivo de eucalipto em propriedades rurais: diversificação e produção de renda. Ttflorestal. Cap. 1. Pág. 11. EMBRAPA. BrasíliaDF. 2014.

RADOMSKI, M. I.; RIBASKI, J. Excentricidade da medula em Grevilea robusta e Corymbiacitriodora cultivados em sistema silvipastoril. Embrapa Florestas-Comunicado Técnico (INFOTECA-E), 2010.

REIS, C.A.R.; ASSIS, T.F.; SANTOS, A.M.; PALUDZYSZYN FILHO. E. Corymbia citriodora: estado da arte de pesquisas no Brasil, Colombo, Embrapa Florestas, 2013.

RIBASKI, J.; RADOMSKI, M. I.; PORFÍRIO-DASILVA, V. Sistemas silvipastoris em propriedades rurais no Noroeste do Estado do Paraná. Embrapa Florestas-Capítulo em livro científico (ALICE), 2019.

RIBEIRO, G. B. de D.; ISBAEX, C.; VALVERDE, S. R. Produção de biomassa florestal para energia em sistemas agroflorestais. Pesquisa Florestal Brasileira, v. 37, n. 92, p. 605-618, 1983-2605 2017.

RIBEIRO, H.; JAIME, P. C.; VENTURA, D. Alimentação e sustentabilidade. Estud. av. São Paulo, v. 31, n. 89, pág. 185-198, 0103-4014 2017.

RODRIGUES, L. M.; Teodoro, A.G.; Santos, A.J.M.; Backes, C.; Rocha, J.H.T.; Giongo, P.R.; dos Santos, Y.L.A. Integração Lavoura-PecuáriaFloresta: Interação entre Componentes e Sustentabilidade do Sistema. Archivos de zootecnia, v. 68 , n. 263 , p. $448-455,1885-4494$ 2019.

SANTANA, E. A. R.; Andrighetto, C.; MATEUS, G. P.; ARANHA, A. S.; LUPATINI, G. C.; MEIRELLES, P. R. L.; ARANHA, H. S.; SANTOS, J. M. F.; LUZ, P. A. C; TRIVELIN, G. A. Padrão de deslocamento de bovinos Nelore em sistemas integrados de produção agropecuária. Arquivo Brasileiro de Medicina Veterinária e Zootecnia, v. 71, n. 1, p. 353356, 1678-4162, 2019.

SANTOS, P. E. T. dos; PALUDZYSZYN FILHO, E. Critérios para escolhas de eucaliptos para plantio. 
Ttflorestal. Cap 3. Pag 23. EMBRAPA. Brasilia- DF. 2014.

SILVA, A. R.; RODRIGUES FILHO, J. A.; CARVALHO, E. J. M.; SANTIAGO, A. V.; VELOSO, C. A. C.; MARTINEZ, G. B. Estoque de carbono e mitigação de metano produzido por bovinos em sistema integração pecuária-floresta (IPF) com eucalipto no Sudeste Paraense. Brazilian Journal of Development, v. 7 , n. 4, p. 39997-40016, 25258761, 2021.

SILVA, A. R., \& SCHWARTZ, G. Sobrevivência e crescimento inicial de espécies florestais em sistema de integração lavoura-pecuária-floresta no leste da Amazônia. Embrapa Amazônia OrientalArtigo em periódico indexado (ALICE) 2019. Rev. Agro. Amb., v. 12, n. 1, p. 45-63, 1807-1929, 2019.

SILVA, J. M. P.; CAVICHIOLI, F. A. O uso da agricultura 4.0 como perspectiva do aumento da produtividade no campo. Revista Interface Tecnológica, FATEC Taquaritinga, v. 17, n. 2, p. 616-629, 2447-3980, 2020.

SILVA, M. A. da; SILVA, M.L.N.; CURI, N.; AVANZI, J. C.; LEITE, F. P. Sistemas de manejo em plantios florestais de eucalipto e perdas de solo e água na região do Vale do Rio Doce, MG. Ciência Florestal, pag. 765-776.1980-5098, 2011.

SILVA, M.; SILVA, M.; CURI, N.; AVANZI, J.; LEITE, F. Sistemas de manejo em plantios florestais de eucalipto e perdas de solo e água na região do Vale do Rio Doce, MG. Ciência Florestal, 21(4). 19805098, 2011.

SILVA, N. G.; SILVA, C. V. Percepção dos produtores rurais sobre os sistemas integrados na produção agropecuária (SIPAs). Revista Brasileira de Engenharia de Biossistemas, v. 14, n. 2, p. 172186, 2359-6724, 2020.

SILVA, R. L. da; XAVIER, A.; LEITE, H. G.; PIRES, I. E. Determinação do tamanho ótimo da parcela experimental pelos métodos da máxima curvatura modificado, do coeficiente de correlação intraclasse e da análise visual em testes clonais de eucalipto. Revista Árvore, Viçosa, v. 27, n. 5, p. 669-676, 0100-6762, 2003.

SOUZA, A. F.; ROCHA JUNIOR, E. de O.; LAURA, V. A. Desenvolvimento inicial e eficiência de uso de água e nitrogênio por mudas de Calophyllum brasiliense, Eucalyptus urograndis, Tabebuia impetiginosa e Toona ciliata. Ciência Florestal, v. 28, n. 4, p. 1465-1477, 1980-5098, 2018.

SKORUPA, L. A.; MANZATTO, C. V. Avaliação da adoção de sistemas de integração lavoura- pecuária-floresta (ILPF) no Brasil. Embrapa Meio Ambiente-Capítulo em livro científico (ALICE), 2019.

SNIF. Sistema Nacional de Informações Florestais. Cadeia Produtiva. Cadeia Produtiva. Fev. 2020. https://snif.florestal.gov.br/pt-br/cadeia-produtiva.

TELLES, T. S.; VIEIRA FILHO, J. E. R,; RIGHETTO, A. J.; RIBEIRO, M. R. Desenvolvimento da agricultura de baixo carbono no Brasil. 2021.2 IPEA. http://repositorio.ipea.gov.br/handle/11058/10531.

TOMAZ, G., WANDER, A. Barreiras à adoção do sistema ILPF em Goiás. Revista de Política Agrícola. № 1. 2317-224X, 2017.

TONINI, H.; MORALES, M. M.; DA SILVA, V. P.; LULU, J.; FARIAS NETO, A. L. Efeito do sistema de plantio e da exposição solar sobre a alocação da biomassa no desenvolvimento inicial do eucalipto. Ciência Florestal, v. 29, n. 1, p. 86-95, 1980-5098, 2019.

WEIMANN, C.; FARIAS, J. A. de; DEPONTI, G. Viabilidade econômica do componente arbóreo de sistema agrossilvipastoril comparado ao de plantio florestal na pequena propriedade rural. Pesquisa Florestal Brasileira, v. 37, n. 92, p. 429-436, 19832605, 2017. 